\title{
Green Tea Consumption Lower Damage and Inflammatory Cytokines in Rat Cardiovascular System Under Androgenic Stimulation
}

\author{
Vivian Alves Pereira Silva ${ }^{1}$, Gilson Teles Boaventura ${ }^{2}$, Renato Souza Abboud ${ }^{1}$, \\ José Antonio Silva Ribas ${ }^{3}$, Mauricio Alves Chagas ${ }^{1, *}$ \\ ${ }^{1}$ Biomedical Institute, Federal Fluminense University, Niteroi, Brazil \\ ${ }^{2}$ Nutrition Faculty, Federal Fluminense University, Niteroi, Brazil \\ ${ }^{3}$ Department of Physiology and Pharmacology, Federal Fluminense University, Niteroi, Brazil
}

Email address:

chagas.m@gmail.com (M. A. Chagas)

${ }^{*}$ Corresponding author

\section{To cite this article:}

Vivian Alves Pereira Silva, Gilson Teles Boaventura, Renato Souza Abboud, José Antonio Silva Ribas, Mauricio Alves Chagas. Green Tea Consumption Lower Damage and Inflammatory Cytokines in Rat Cardiovascular System Under Androgenic Stimulation. American Journal of Sports Science. Vol. 7, No. 4, 2019, pp. 141-148. doi: 10.11648/j.ajss.20190704.12

Received: July 29, 2019; Accepted: September 27, 2019; Published: October 10, 2019

\begin{abstract}
The abuse of anabolic androgenic steroids by youth and adolescents, athletes and non-athletes, is related to the occurrence of cardiovascular diseases. Contrastingly, green tea prevents and attenuates the cellular damage, improving the biochemical profile and reducing inflammation. This study aims to evaluate the benefits of consuming green tea to attenuate the inflammatory parameters and the cardiovascular damage, which are caused due to supraphysiological doses of testosterone, by analyzing the serological profile and the histoarchitecture of the heart and the arteries of 28 42-day-old male Wistar rats. Silicone pellets containing testosterone were surgically implanted and replaced every four weeks. After 20 weeks, all the male rats were anesthetized and their blood samples collected for serological analysis. Fragments of the aorta, left cardiac ventricle and penis were excised and processed to paraffin. To access morphometrical and stereological parameters, tissue fragments were stained and the images analyzed employing Image $\mathbf{J}$ software. The rats consuming green tea exhibited a reduction in aorta wall thickness (22\%), luminal area (40\%) and wall area (52\%), with a lower number of elastic lamella. The dorsal artery of the penis presented with a higher wall area and lower luminal area in induced group compared to the other three groups. Tea consumption also led to a significant reduction in the left ventricle thickness with no increase in volumetric density of collagen fibers. Inflammatory cytokines were also shown to have increased in induced group, indicating cardiovascular risk due to their exposure to testosterone. Except for the endothelial vascular growth factor, this effect was not observed in the groups that consumed tea. It can be concluded that the consumption of green tea has a protective effect on the morphology of cardiovascular tissues and reduces inflammatory indicators, which points out this food as an agent capable of reducing cardiovascular disease risk factors related to high doses of anabolic androgenic steroids.
\end{abstract}

Keywords: Cardiovascular Diseases, Testosterone, Green Tea, Morphometry, Cytokines

\section{Introduction}

Abuse of androgenic anabolic steroids has been on the rise since the 1990s, and today children, adolescents and young people use supraphysiological doses of these substances, especially in the context of high-performance athletes [1-5]. Long-term indiscriminate use of steroids causes severe morphophysiological changes in the cardiovascular system $[6,7]$. Previous studies have shown a positive association between the use of testosterone as a steroid anabolic and the development of cardiovascular disease (CVD) [8, 9]. Clinical consequences of the random use of anabolic steroids include increased blood pressure, thrombosis, dyslipidemia, stroke, cardiac hypertrophy, and myocardial infarction, as well as other dysfunctions that affect various organic systems. 
Excessive use of testosterone can culminate in the user's death even without a history of disease [2, 5, 10-14].

The occurrence of CVD associated with supraphysiological levels of testosterone is strongly related to the inflammatory process that occurs in the heart and the vessels of Wistar rats. Among the major inflammatory markers of CVD belong tumor necrosis factor-alpha (TNF- $\alpha$ ) [15] and monocyte chemoattractant protein-1 (MCP-1) [16], which are acute phase markers, and vascular endothelial growth factor (VEGF), which indicates angiogenesis and tissue repair [17].

In contrast, regular consumption of nutraceutical foods promotes general improvement of organic functions, reducing body fat and, consequently, improving weight loss. Green tea (Camellia sinensis) is one of the most popular beverages widely consumed throughout the world. This nutraceutical comprises polyphenols, bioflavonoids and tannin besides micronutrients such as manganese, folic acid, potassium and vitamins $\mathrm{C}, \mathrm{K}, \mathrm{B} 1$ and B2 [18]. The aforementioned components act on the body's systems and can reduce and/or retard the severity or evolution of some diseases [19]. The health benefit effects of green tea are mainly related to high concentrations of polyphenols, which are also known as catechins. Green tea contains five major catechins: catechin, epicatechin, epicatechin gallate, epigallocatechin and epigallocatechin gallate (EGCG); the latter comprises more than $40 \%$ of the total polyphenolic mixture of green tea catechins. The polyphenols from green tea are capable of altering lipids and cholesterol metabolism and have antioxidant, anti-inflammatory properties [20], cancer, cardiovascular disease prevention [11, 21] and anabolic anti-obesity properties [22]. In addition, green tea polyphenols (mainly EGCG) have an anti-androgenic effect, whereby they modulate the metabolism of testosterone [23]. Based on these properties, green tea consumption may be indicated as prophylaxis or auxiliary therapy for several diseases, mainly CVD.

Thereby, this study aims to evaluate the effects of green tea consumption as a nutraceutical food, on the damage to the cardiovascular system of Wistar rats, caused by the use of supraphysiological doses of testosterone, evaluating the morphometric effects and the inflammatory profile of TNFalpha, MCP-1 and VEGF, and using the heart, aorta (elastic artery) and the dorsal artery of the penis (muscular artery) as comparative arterial models for the study.

\section{Materials and Experiments}

\subsection{Animals}

The use of animals for this study was approved by the Animal Use Ethics Committee of the Federal Fluminense University (RJ, Brazil) under the protocol, CEUA-UFF-765/2016. Materials from 28 adult male Wistar rats aged 42-50 days were used. The rodents in this study were subdivided into four groups of seven rodents each and arranged as follows: control group (CG) - animals hydrated with water; green tea group (GTG) - animals hydrated with green tea; induced group (IG) - animals that were administered with testosterone and hydrated with water; and induced green tea group (IGTG) - animals that were administered with testosterone and hydrated with green tea. The rodents were housed in individual plastic cages at a 12:12-h light/dark cycle and a constant temperature of $22 \pm 1^{\circ} \mathrm{C}$, with free access to water or green tea, and were administered with casein-based feed, ad libitum. Body weight and feed and water/green tea intakes were monitored weekly. At the beginning of the experiment, the mean body weight of the animals was $260 \pm 10 \mathrm{~g}$.

\subsection{Induction}

Induction with testosterone was performed using silicone pellets (Dow Corning, cat. no. 508-009 Silastic ${ }^{\mathrm{TM}}$ Tube, 1.98 $\mathrm{mm} \mathrm{I}$. D. $\times 3.18 \mathrm{~mm}$ O. D., $5 \mathrm{~cm}$ long) filled with testosterone propionate $(1 \mathrm{mg})$ and sealed with a surgical adhesive [24]. The rodents were anesthetized intraperitoneally with xylazine $(10 \mathrm{mg} / \mathrm{kg})$ and ketamine $(75 \mathrm{mg} / \mathrm{kg})$, and the pellets were implanted in their dorsal scapular region with an incision of approximately $10 \mathrm{~mm}$. For a skin synthesis, a cyanoacrylatebased surgical adhesive was used. The pellets were replaced every four weeks for 20 weeks.

\subsection{Control Feed}

The control casein-based feed was prepared according to the pattern used in previous studies from the group [11]. The feed used in this experiment was prepared at the Laboratory of Experimental Nutrition (Federal Fluminense University, Niteroi, Brazil). Every $100 \mathrm{~g}$ of feed had a vitamin and mineral mix added to it, and the amounts of nutrients are based on the recommendations of the American Institute of Nutrition (AIN-93M) [25] for animals in this stage of development. The ingredients of the casein-based feed (Table 1) were weighed and homogenized with boiling water for starch gelatinization, using an industrial mixer (Hobart ${ }^{\circledR}$, São Paulo, SP, Brazil). The resultant dough, after identification, was transformed into pellets and dried in a ventilated incubator (Fabbe-Primar ${ }^{\circledR} \mathrm{n}^{\circ} 171$, São Paulo, SP, Brazil) at $60^{\circ} \mathrm{C}$ for $24 \mathrm{~h}$ and stored under refrigeration until use.

Table 1. Nutritional composition of casein-based feed used in the study.

\begin{tabular}{lll}
\hline Nutrients & Ingredients $^{\dagger}$ & g/100g \\
\hline Protein & Casein $^{\mathrm{a}}$ & 14,00 \\
Carbohydrates & Starch $^{\mathrm{b}}$ & 58,95 \\
& Refined sugar $^{\mathrm{c}}$ & 10,00 \\
Minerals & Mineral mix $^{\text {a }}$ & 3,50 \\
Vitamins & Vitamin mix $^{\text {a }}$ & 1,00 \\
Fat & Soybean Oil $^{\mathrm{d}}$ & 7,00 \\
Fiber & Cellulose $^{\mathrm{e}}$ & 5,00 \\
Essential amino acids & Choline bitartarate $^{\text {a }}$ & 0,25 \\
& Cystine $^{\text {a }}$ & 0,30 \\
Food stabilizer & Tert-Butylhydroquinone $^{\text {a }}$ & 0,0014 \\
\hline
\end{tabular}

$\dagger$ Ingredients supplied by: [a] M. Cassab Industry and Commerce Limited (Sao Paulo, SP, Brazil). [b] Maizena Unilever Bestfoods Brazil Limited (Mogi Guaçu, SP, Brazil); [c] União (Rio de Janeiro, RJ, Brazil); [d] Liza Cargill Agriculture Limited (Mairinque SP, Brazil); [e] Microcel Blanver Limited (Cotia, SP, Brazil). 


\subsection{Green Tea Preparation}

The tea was prepared infusing the leaves of Camellia sinensis (Yamamotoyama-Midori $\mathrm{n}^{\circ} 262$, Sao Miguel Arcanjo, SP, Brazil) at a concentration of $2 \%$, which was calculated by weight/volume [11] - $20 \mathrm{~g}$ of leaves were used for $1000 \mathrm{ml}$ of water. In this protocol, the leaves are infused for two minutes and, then, the tea is filtered and cooled immediately. The animals in the green tea groups had their hydration exclusively through tea, and the supply was 200 $\mathrm{ml} /$ day.

\subsection{Blood Collection and Sample Processing}

At the end of the experimental period at the bioterium, the animals were euthanized. The rodents were anesthetized with $75 \mathrm{mg} / \mathrm{kg}$ of ketamine plus $10 \mathrm{mg} / \mathrm{kg}$ de xylazine, and the calculated dose was intraperitoneally administered. After the realization of the anesthetic condition through the absence of pedal reflex, the rats were then made to bleed by intracardiac puncture, and $10 \mathrm{ml}$ of blood was obtained. After bleeding, an additional dose of the anesthesia was administered, which led to the death of the rodent. Blood samples collected lacking anticoagulant were held for about two hours at room temperature for clot retraction. Thereafter, they were centrifuged at $958.5 \mathrm{~g}$ for five minutes to obtain the serum and stored at $-20^{\circ} \mathrm{C}$. To evaluate the success of the induction, the serum testosterone was measured by radioimmunoassay (RIA) using a commercial, solid-state Beckman Coulter kit (Immunotech ${ }^{\circledR}$ ). The tests were performed in the laboratory of the Brazilian Institute of Diagnosis and Veterinary Specialties (PROVET, Sao Paulo, Brazil), using the Perkin Elmer (RIA) WIZARD2 equipment.

\subsection{Determination of TNF-alpha, MCP-1 and VEGF}

Analysis of TNF-alpha, MCP - 1 and VEGF were assessed using the Milliplex Map Rat Cardiovascular Disease Panel 1 (RCVD1-89K-02 from Millipore $\AA$ ) in the Luminex TM 200 device [26]. These analyses were performed in the Specialized Laboratory of Scientific Analyses (LEAC, Sao Paulo, Brazil).

\subsection{Histological Procedures}

The tissue fragments obtained from rat thoracic aorta, cardiac ventricles and penis were fixed in buffered formaldehyde (formalin of Millonnig) for $24 \mathrm{~h}$ and processed according to standard histological technique for paraffin. After including the fragments of the aorta, penis and cardiac ventricles, the paraffin blocks were cut in microtome RM2125RT (Leica ${ }^{\circledR}$ ) in $5 \mu \mathrm{m}$ sections and mounted on glass slides for optical microscopy. The slides were stained by Hematoxylin-eosin (overall), Weigert's Resorcin Fuchsin (elastic fiber staining) and picrosirius red (collagen fiber staining). A morphometrical analysis was performed by capturing images of the histological sections through a microscope, Olympus BX51®, coupled to a digital camera, Olympus DP72®, using 4, 20 and 40X objective. Histomorphometry scan was used to measure the thickness of the aorta, the luminal area and the wall area of the aorta and the dorsal artery of the penis and the left ventricle thickness through software Image $\mathrm{J}{ }^{\circledR}$ (U.S. National Institutes of Health, Bethesda, Maryland, USA). To determine the number of elastic lamella in the aorta wall, cell counter plug-in from Image $J \mathbb{B}$ software was used.

\subsection{Stereological Analysis}

The slides containing the tissue sections of the cardiac ventricles were stained with picrosirius red for fibrillar staining of collagen. The images were captured for a LG 14" monitor with a superposed M42 test system [27]. The volumetric density - Vv (\%) - of the collagen was determined.

\subsection{Statistical Analysis}

The data were presented under the average and standard deviation forms. The Kolmogorov-Smirnov test was deployed to test the normal distribution of the values and the ANOVA univariate for data analysis, which is associated with the Tukey-Kramer multiple comparison test. The significance in all the conducted tests was established to the level of $\mathrm{p}<0.05$, and the statistical analyses were performed by the Graph Pad Prism version 5.0, 2007 (San Diego, C. A., U.S.A.) program.

\section{Results}

\subsection{Testosterone}

The values of serum testosterone were increased in the induced group $(661,4 \pm 173,4 \mathrm{ng} / \mathrm{dL})$, when compared with the control group $(314,4 \pm 74,2 \mathrm{ng} / \mathrm{dL})$ and the tea groups (GTG $332,3 \pm 128,6$ and IGTG $270,4 \pm 127,1 \mathrm{ng} / \mathrm{dL})$. The significance of the statistic test ( $p$ value) was $p<0,0001$ (Figure 4).

\subsection{Morphometrical and Morphological Changes in Cardiovascular Tissues}

After 20 weeks of study, a thickness of the aorta accompanied by an increased wall area was observed in the induced group. An increase in the luminal area of the aorta (Figure 1) was found as well. In the tea groups (GTG and IGTG), a reduced number of elastic lamella was found (Table 2), which was better organized and compacted to that in IG (Figure 2). The dorsal artery of the penis (DAP) showed an increase in the wall area and a reduction in the luminal area in the induced group (Table 2) compared to other groups (Figure 3). The left cardiac ventricle presented with a thickening in the IG. The tea groups found a reduction in the volumetric density of collagen (Table 2). 
Table 2. Morphometric and stereological parameters observed in an elastic artery (Aorta), a muscular artery (dorsal artery of the penis) and in the heart left ventricle.

\begin{tabular}{lllllll}
\hline \multirow{2}{*}{ Parameter } & & Groups $^{\dagger}$ & & & \\
\cline { 3 - 6 } & & CG & IG & GTG & IGTG & \multirow{2}{*}{ P Value } \\
\hline \multirow{4}{*}{ Aorta } & Luminal area $\left(\mathrm{mm}^{2}\right)$ & $1,93 \pm 0,4$ & $2,64 \pm 0,6^{*}$ & $1,85 \pm 0,11$ & $1,63 \pm 0,08$ & 0,0001 \\
& Wall thickness $(\mu \mathrm{m})$ & $131,7 \pm 12$ & $156,3 \pm 12^{*}$ & $124,3 \pm 7$ & $122,2 \pm 11$ & 0,0001 \\
& Wall area $\left(\mathrm{mm}^{2}\right)$ & $1,18 \pm 0,14$ & $1,38 \pm 0,15^{*}$ & $0,71 \pm 0,06^{*}$ & $0,65 \pm 0,06^{*}$ & 0,0001 \\
\multirow{2}{*}{ DAP } & Elastic lamella $($ units/area) & $9,5 \pm 1,2$ & $9,7 \pm 1,2$ & $8,0 \pm 0,7^{*}$ & $7,6 \pm 0,3^{*}$ & 0,0003 \\
& Luminal area $\left(\mu \mathrm{m}^{2}\right)$ & $4042,1 \pm 826,6$ & $2875,8 \pm 1003,3^{*}$ & $3896,9 \pm 1026,4$ & $3907,5 \pm 878,4$ & 0,0375 \\
\multirow{2}{*}{ Heart } & Wall area $\left(\mu \mathrm{m}^{2}\right)$ & $5431,1 \pm 271,3$ & $6648,1 \pm 1162,5^{*}$ & $5717,2 \pm 468,5$ & $5620,7 \pm 305,5$ & 0,0076 \\
& Miocardic thickness $(\mathrm{mm})$ & $2,62 \pm 0,2$ & $3,08 \pm 0,3^{*}$ & $2,98 \pm 0,09$ & $3,14 \pm 0,3^{*}$ & 0,0036 \\
\hline
\end{tabular}

Obtained from ANOVA univariate test, associated to the Tukey-Kramer multiple comparison test. Data presented under the average and standard deviation forms. Number of animals in each group (n): 7. (*) Significant differences compared to control group (CG). ( $\left(^{\dagger}\right) \mathrm{CG}$ - Control group; IG - Induced group; GTG - Green tea group; IGTG - Induced green tea group; $\left({ }^{\ddagger}\right) \mathrm{DAP}$ - Dorsal artery of the penis; $\left({ }^{\S}\right) \mathrm{Vv}$ - Volumetric density.

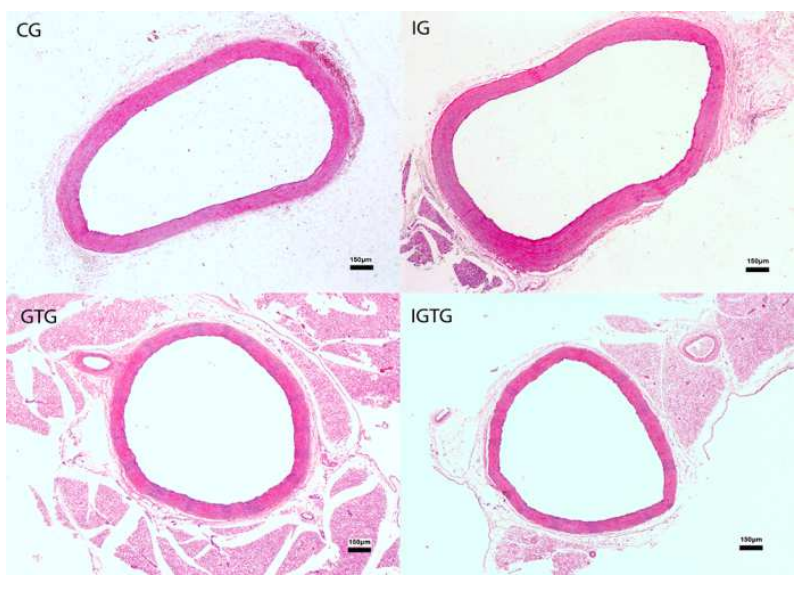

Figure 1. Histological images of the aorta (elastic artery).

Hematoxylin-eosin staining. Images of cross sections of the aorta of Wistar rats, obtained using $4 \mathrm{X}$ objective. Calibration bar measuring 100 micrometers. CG - Control group; IG - Induced group; GTG - Green tea group; IGTG - Induced green tea group.

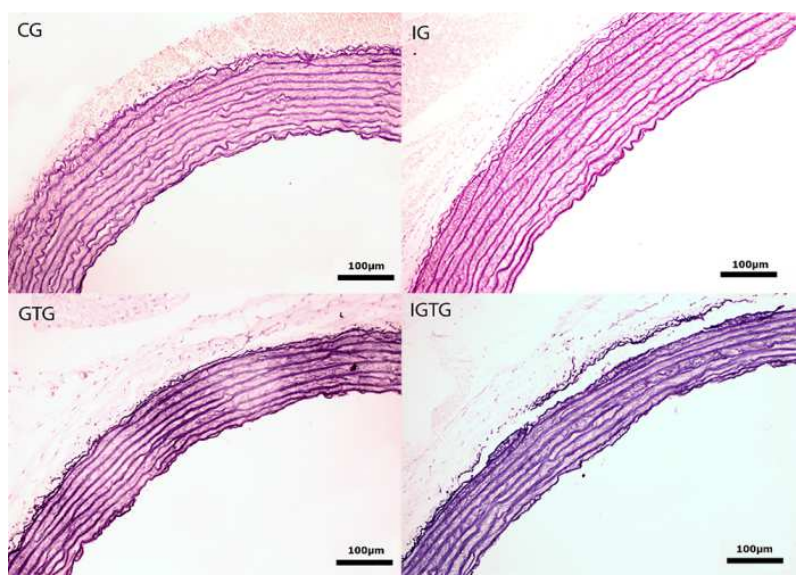

Figure 2. Histological images of the aorta, evidencing elastic lamella.

Weigert's Fuchsin-Resorcin staining. Images of cross sections of the aorta of Wistar rats, obtained using $20 \mathrm{X}$ objective. Calibration bar measuring 150 micrometers. CG - Control group; IG - Induced group; GTG - Green tea group; IGTG - Induced green tea group

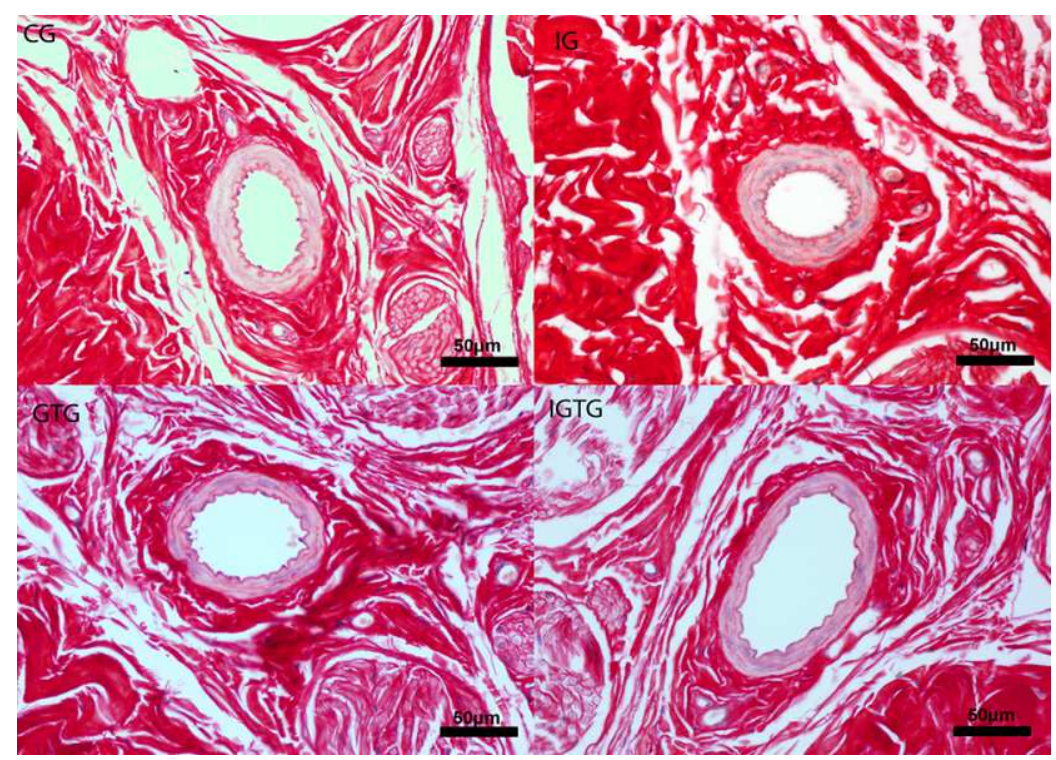

Figure 3. Histological images of the dorsal artery of the penis (muscular artery).

Picrosirius red staining. Images of cross sections of the penis, evidencing dorsal artery of the penis of Wistar rats, obtained using $40 \mathrm{X}$ objective. Calibration bar measuring 50 micrometers. CG - Control group; IG - Induced group; GTG - Green tea group; IGTG - Induced green tea group. 


\subsection{Inflammatory Cytokines}

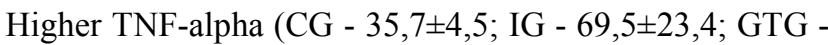
$34,3 \pm 5,3 ;$ IGTG - 39,1 $\pm 6,0 \mathrm{pg} / \mathrm{mL}$ ) and MCP-1 (CG -

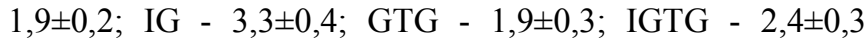
$\mathrm{ng} / \mathrm{mL}$ ) serum concentrations in IG were found compared to the control group. These effects were found to be reversed in the tea-induced group. An increase in the serum VEGF values in the induced groups (IG - 4,2 $\pm 0,9$ and IGTG $6,1 \pm 0,8 \mathrm{ng} / \mathrm{mL})$ was observed compared to $\mathrm{CG}(1,8 \pm 0,6$ $\mathrm{ng} / \mathrm{mL})$ and $\mathrm{GTG}(2,8 \pm 0,9 \mathrm{ng} / \mathrm{mL})$, despite the addition of the green tea to the diet (Figure 4).

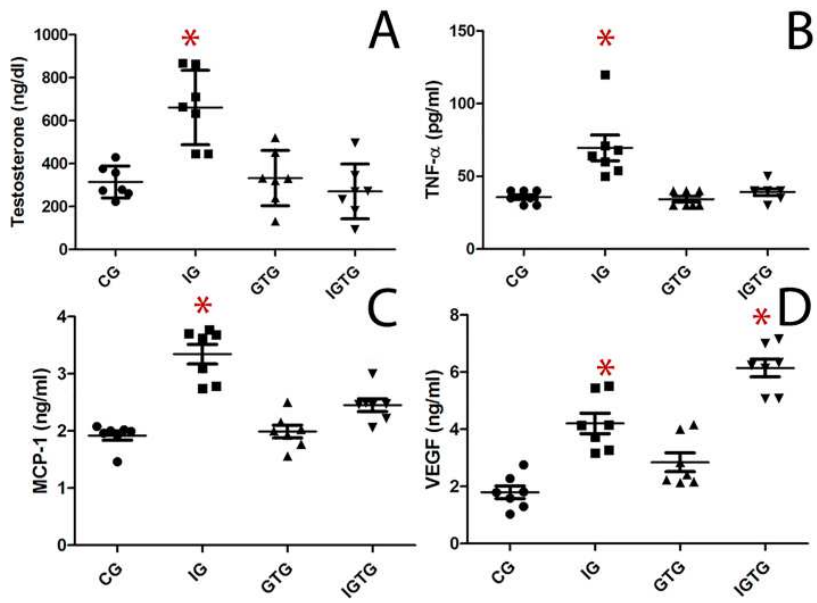

Figure 4. Serological profile of evaluated inflammatory cytokines (TNFalpha, MCP-1 and VEGF) and serum testosterone.

(*) Significant differences when compared to the control group (GC). Number of animals in each group (n): 7. A) Serum testosterone (pvalue $<0,0001$ ); B) Serum TNF-alpha (p-value $<0,0001$ ); C) Serum MCP-1 (p-value $<0,0001$ ); D) Serum VEGF (p-value $<0,0001$ ). CG - Control group; IG - Induced group; GTG - Green tea group; IGTG - Induced green tea group.

\section{Discussion}

Serum testosterone concentration in the control group was found to be similar to the reference values for Wistar rats [28]. Increased testosterone concentration in the IG shows that the induction was satisfactory. The IGTG presented low serum testosterone values; however these values close to those of the control group. These data confirm the literature, demonstrating the anti-androgenic effects of the consumption of polyphenols extracted from green tea, either by the modulation of the 5alpha-reductase enzyme or other pathways [23, 29].

Thickening of the aorta arterial wall, observed in the IG, indicates vascular damage and is expected to occur with the use of androgenic anabolic steroids, since the administration of testosterone in high doses can lead to obstructive diseases in the arteries due to vasoconstricting effects [30], which may occur due to proliferation of muscle cells or deposition of other tissue components [31]. This action of anabolic steroids on vascular reactivity has consequences for blood pressure [32]. Regarding animal models, the same result was seen in females receiving testosterone after ovariectomy [33]. Contrarily, reduction in the thickness and the aorta wall observed in tea groups, corroborating with the studies of Orozco-Sevilla [34] and Antonello [35], which found that EGCG can inhibit intima hyperplasia, reducing vascular wall, besides improving vascular function as a whole.

The elastic lamella was reduced in tea groups, even in the presence of the high levels of androgens. In GTG and IGTG, these elastic compounds were found to be better organized and compacted compared to those in the IG. Testosterone does not have a great influence on the number of elastic lamella of the aorta; however, green tea consumption has a positive effect on this parameter, which was also confirmed by Vlachopoulos et al. [36], who showed that both green tea and its isolated catechins have an effect of elasticity improvement and cellular response to the stimulus for vessel contraction and relaxation.

The analysis of muscular artery, the dorsal artery of the penis (DAP), showed similar results to those found in the aorta. Despite the differences between aorta and ADP in the tissue content of the tunica media, the high levels of androgens led to a thickening of the arterial wall and a reduction of the luminal area of the ADP in the IG, changes that indicated vascular disease. This result is confirmed for several studies that showed the relation between steroid abuse and severe vascular disease [8, 12, 13, 33, 37]. These changes were not visualized in the animals of the green tea groups, suggesting that polyphenols in green tea may also have a positive effect on the ADP, even with induction. Similar results were found in old or diabetic animals, where administration of green tea was seen to reduce oxidation effects, decreasing vascular damage in the penile vasculature $[20,38]$.

Several studies (both in human and animal models) have shown that androgens have an anabolic effect over the cardiac striated muscle and promote hypertrophy, which was found to be associated to an impairment in the systolic/diastolic ventricular function and increased susceptibility of cardiac ischemia, cell death and reperfusion injury $[12,13,39,40]$. Considering these data, a ventricular wall thickening is expected in the induced animals. However, this study showed that this thickening was not associated with collagen deposition in the tissue. In contrast, it has been shown that green tea components improve the response of cardiac tissue to the noxious stimulus, and this effect was visualized in tea groups. Green tea consumption is perceived as a protective factor for the cardiac tissue as it can reduce the risk of irreversible damage to cardiomyocytes and endothelial cells $[35,41]$.

The results of the serological analysis agree with those of the morphometrical analysis. The increase of acute-phase inflammatory cytokines, TNF-alpha and MCP-1, in the induced group shows that testosterone is promoting inflammation, with a harmful effect on the cardiovascular system. Using different study methods, the results were found to be similar; furthermore, in addition to promoting the 
recruitment and differentiation of lymphocytes, and the production of other inflammatory cytokines, both TNF-alpha and MCP-1 were found to be linked to the rapid and severe evolution of diseases of different organic systems, including the cardiovascular system [16, 42-44]. The consumption of green tea, however, shows the ability to modulate this deleterious effect, reducing the concentration of these cytokines in the induced animals. Green tea polyphenols reduce oxidative damage and may decrease the production of these cytokines, thereby attenuating the inflammatory potential and reducing the risk of CVD $[45,46]$.

Receptor tissue expression and serum VEGF concentration are expected to elevate in the presence of androgens due to the inflammatory process and pro-angiogenic effect promoted by testosterone [47-49]. This study found green tea has a stimulating effect on the production of VEGF. This increase, however, is considered positive and corroborates with the studies of Machova-Urdzikova et al. [50], who observed an increase in VEGF stimulated by green tea polyphenols associated with post-injury tissue recovery. Higher levels of VEGF in the tea groups, associated with reduced inflammatory cytokines, indicate the protective effect of tea on blood vessels and cardiac tissue, reducing the deleterious effects of the inflammatory process.

\section{Conclusion}

In conclusion, the consumption of green tea shields the morphology of cardiovascular tissues, reducing arterial and left ventricular thickness. Tea consumption also led to a reduction in pro-inflammatory indicators TNF-alpha and MCP-1, thus reducing cardiovascular risk factors related to the supraphysiological doses of testosterone. Furthermore, this approach is safe and can be recommended as complementary therapy for CVD and other diseases.

\section{Conflict of Interest}

None of the authors had any conflict of interest.

\section{Funding}

This work was supported by the Fundação de Amparo à Pesquisa do Estado do Rio de Janeiro (FAPERJ) and the Coordenação de Aperfeiçoamento de Pessoal de Nível Superior (CAPES), Brazil, Finance Code 001.

\section{References}

[1] Maravelias, C., A. Dona, M. Stefanidou, and C. Spiliopoulou, "Adverse effects of anabolic steroids in athletes. A constant threat". Toxicol Lett, 158 (3), 2005, pp. 167-75.

[2] Luijkx, T., B. K. Velthuis, F. J. Backx, C. F. Buckens, N. H. Prakken, R. Rienks, W. P. Mali, and M. J. Cramer, "Anabolic androgenic steroid use is associated with ventricular dysfunction on cardiac MRI in strength trained athletes". Int J Cardiol, 167 (3), 2013, pp. 664-8.
[3] Piacentino, D., G. D. Kotzalidis, L. Longo, A. Pavan, L. Stivali, G. Stivali, S. Ferracuti, R. Brugnoli, P. Frati, V. Fineschi, P. Girardi, and G. Sani, "Body Image and Eating Disorders are Common among Professional and Amateur Athletes Using Performance and Image Enhancing Drugs: A Cross-Sectional Study". J Psychoactive Drugs, 49 (5), 2017, pp. 373-384.

[4] Nicholls, A. R., E. Cope, R. Bailey, K. Koenen, D. Dumon, N. C. Theodorou, B. Chanal, D. Saint Laurent, D. Muller, M. P. Andres, A. H. Kristensen, M. A. Thompson, W. Baumann, and J. F. Laurent, "Children's First Experience of Taking AnabolicAndrogenic Steroids can Occur before Their 10th Birthday: A Systematic Review Identifying 9 Factors That Predicted Doping among Young People". Front Psychol, 8, 2017, pp. 1015.

[5] Lichtenfeld, J., B. J. Deal, and S. Crawford, "Sudden cardiac arrest following ventricular fibrillation attributed to anabolic steroid use in an adolescent". Cardiol Young, 26 (5), 2016, pp. 996-8.

[6] dos Santos, R. L., F. B. da Silva, R. F. Ribeiro, Jr., and I. Stefanon, "Sex hormones in the cardiovascular system". Horm Mol Biol Clin Investig, 18 (2), 2014, pp. 89-103.

[7] Sader, M. A., K. A. Griffiths, R. J. McCredie, D. J. Handelsman, and D. S. Celermajer, "Androgenic anabolic steroids and arterial structure and function in male bodybuilders". J Am Coll Cardiol, 37 (1), 2001, pp. 224-30.

[8] Hartgens, F. and H. Kuipers, "Effects of androgenic-anabolic steroids in athletes". Sports Med, 34 (8), 2004, pp. 513-54.

[9] Yeap, B. B., "Sex steroids and cardiovascular disease". Asian J Androl, 16 (2), 2014, pp. 239-47.

[10] Montisci, M., R. El Mazloum, G. Cecchetto, C. Terranova, S. D. Ferrara, G. Thiene, and C. Basso, "Anabolic androgenic steroids abuse and cardiac death in athletes: morphological and toxicological findings in four fatal cases". Forensic Sci Int, 217 (1-3), 2012, pp. 13-8.

[11] Silva, V. A. P., G. T. Boaventura, R. S. Abboud, J. A. S. Ribas, and M. A. Chagas, "Consumption of Green Tea (Camellia sinensis) Improves Lipid, Hepatic, and Hematological Profiles of Rats That Are Submitted to Long-Term Androgenic Stimulation". American Journal of Sports Science, 6 (4), 2018, pp. 6.

[12] Frati, P., F. P. Busardo, L. Cipolloni, E. D. Dominicis, and V. Fineschi, "Anabolic Androgenic Steroid (AAS) Related Deaths: Autoptic, Histopathological and Toxicological Findings". Curr Neuropharmacol, 13 (1), 2015, pp. 146-59.

[13] Baggish, A. L., R. B. Weiner, G. Kanayama, J. I. Hudson, M. T. Lu, U. Hoffmann, and H. G. Pope, Jr., "Cardiovascular Toxicity of Illicit Anabolic-Androgenic Steroid Use". Circulation, 135 (21), 2017, pp. 1991-2002.

[14] Choi, B. G. and M. A. McLaughlin, "Why men's hearts break: cardiovascular effects of sex steroids". Endocrinology and metabolism clinics of North America, 36 (2), 2007, pp. 365377.

[15] Ridker, P. M., N. Rifai, M. Pfeffer, F. Sacks, S. Lepage, and E. Braunwald, "Elevation of tumor necrosis factor- $\alpha$ and increased risk of recurrent coronary events after myocardial infarction". Circulation, 101 (18), 2000, pp. 2149-2153. 
[16] Welt, F. G., C. Tso, E. R. Edelman, M. A. Kjelsberg, J. F. Paolini, P. Seifert, and C. Rogers, "Leukocyte recruitment and expression of chemokines following different forms of vascular injury". Vasc Med, 8 (1), 2003, pp. 1-7.

[17] Couffinhal, T., M. Kearney, B. Witzenbichler, D. Chen, T. Murohara, D. W. Losordo, J. Symes, and J. M. Isner, "Vascular endothelial growth factor/vascular permeability factor (VEGF/VPF) in normal and atherosclerotic human arteries". Am J Pathol, 150 (5), 1997, pp. 1673-85.

[18] Sang, S., J. D. Lambert, C. T. Ho, and C. S. Yang, "The chemistry and biotransformation of tea constituents". Pharmacol Res, 64 (2), 2011, pp. 87-99.

[19] Yokozawa, T., J. S. Noh, and C. H. Park, "Green Tea Polyphenols for the Protection against Renal Damage Caused by Oxidative Stress". Evid Based Complement Alternat Med, (845917), 2012.

[20] Mostafa, T., D. Sabry, A. M. Abdelaal, I. Mostafa, and M. Taymour, "Cavernous antioxidant effect of green tea, epigallocatechin-3-gallate with/without sildenafil citrate intake in aged diabetic rats". Andrologia, 45 (4), 2013, pp. 272-7.

[21] Cheng, H., N. Xu, W. Zhao, J. Su, M. Liang, Z. Xie, X. Wu, and Q. Li, "(-)-Epicatechin regulates blood lipids and attenuates hepatic steatosis in rats fed high-fat diet". Mol Nutr Food Res, 61 (11), 2017.

[22] Meydani, M. and S. T. Hasan, "Dietary polyphenols and obesity". Nutrients, 2 (7), 2010, pp. 737-51.

[23] Hiipakka, R. A., H. Z. Zhang, W. Dai, Q. Dai, and S. Liao, "Structure-activity relationships for inhibition of human 5alpha-reductases by polyphenols". Biochem Pharmacol, 63 (6), 2002, pp. 1165-76.

[24] de Amorim Ribeiro, I. C., C. A. S. da Costa, V. A. P. da Silva, L. B. N. S. Côrrea, G. T. Boaventura, and M. A. Chagas, "Flaxseed reduces epithelial proliferation but does not affect basal cells in induced benign prostatic hyperplasia in rats". European Journal of Nutrition, 56 (3), 2017, pp. 1201-1210.

[25] Reeves, P., F. Nielsen, and G. Gahey, "AIN-93 purified diets for laboratory rodents: final report of the American Institute of Nutrition Ad Hoc Writing Committee on the reformation of the AIN-76A rodent diet". Journal of Nutrition, 132, 1993, pp. 1939-1.

[26] Vicente, G. C., A. M. Correia-Santos, A. Suzuki, M. A. Chagas, and G. T. Boaventura, "Maternal use of a diet rich omega - 3 from flaxseed improves aortic remodeling but not the biochemical parameters of female offspring of diabetic rats". European Journal of Lipid Science and Technology, 117 (3), 2015, pp. 291-299.

[27] Weibel, E. R., G. S. Kistler, and W. F. Scherle, "Practical stereological methods for morphometric cytology". The Journal of cell biology, 30 (1), 1966, pp. 23-38.

[28] Melo, M. G. D. d., G. A. A. Dória, M. R. Serafini, and A. A. d S. Araújo, "Hematological and biochemical reference values of Wistar rats (Rattus novergicus) from the central laboratory of the Federal of Sergipe University." Scientia plena, 8 (9), 2012, pp. 6.

[29] Jenkinson, C., A. Petroczi, and D. P. Naughton, "Effects of Dietary Components on Testosterone Metabolism via UDPGlucuronosyltransferase". Front Endocrinol (Lausanne), 4,
2013, pp. 80

[30] Dobrzycki, S., K. Zukowska-Serwatka, and J. R. Ladny, "[Pathogenetic basis of androgen administration in cardiology]". Pol Merkur Lekarski, 14 (81), 2003, pp. 268-70.

[31] Bastug, O., L. Korkmaz, H. Halis, O. Canoz, and T. Gunes, "Omega-3 fatty acids may be harmful to thickness of aortic intima-media". Bratisl Lek Listy, 116 (4), 2015, pp. 236-40.

[32] Vanberg, P. and D. Atar, "Androgenic anabolic steroid abuse and the cardiovascular system". Handb Exp Pharmacol, (195), 2010, pp. 411-57.

[33] Dorsett-Martin, W. A. and R. L. Hester, "Sex hormones and aortic wall remodeling in an arteriovenous fistula". Gend Med, 4 (2), 2007, pp. 157-69.

[34] Orozco-Sevilla, V., R. Naftalovich, T. Hoffmann, D. London, E. Czernizer, C. Yang, A. Dardik, and H. Dardik, "Epigallocatechin-3-gallate is a potent phytochemical inhibitor of intimal hyperplasia in the wire-injured carotid artery". J Vasc Surg, 58 (5), 2013, pp. 1360-5.

[35] Antonello, M., D. Montemurro, M. Bolognesi, M. Di Pascoli, A. Piva, F. Grego, D. Sticchi, L. Giuliani, S. Garbisa, and G. P. Rossi, "Prevention of hypertension, cardiovascular damage and endothelial dysfunction with green tea extracts". Am J Hypertens, 20 (12), 2007, pp. 1321-8.

[36] Vlachopoulos, C., N. Alexopoulos, I. Dima, K. Aznaouridis, I. Andreadou, and C. Stefanadis, "Acute effect of black and green tea on aortic stiffness and wave reflections". J Am Coll Nutr, 25 (3), 2006, pp. 216-23.

[37] Chistiakov, D. A., V. A. Myasoedova, A. A. Melnichenko, A. V. Grechko, and A. N. Orekhov, "Role of androgens in cardiovascular pathology". Vasc Health Risk Manag, 14, 2018, pp. 283-290.

[38] Neves, D., M. Assuncao, F. Marques, J. P. Andrade, and H. Almeida, "Does regular consumption of green tea influence expression of vascular endothelial growth factor and its receptor in aged rat erectile tissue? Possible implications for vasculogenic erectile dysfunction progression". Age (Dordr), 30 (4), 2008, pp. 217-28.

[39] Seara, F. A. C., R. A. Q. Barbosa, D. F. de Oliveira, D. L. S. Gran da Silva, A. B. Carvalho, A. C. Freitas Ferreira, J. H. Matheus Nascimento, and E. L. Olivares, "Administration of anabolic steroid during adolescence induces long-term cardiac hypertrophy and increases susceptibility to ischemia/reperfusion injury in adult Wistar rats". J Steroid Biochem Mol Biol, 171, 2017, pp. 34-42.

[40] Frantz, S., K. Hu, J. Widder, B. Weckler, H. Scheuermann, J. Bauersachs, G. Ertl, F. Callies, and B. Allolio, "Detrimental effects of testosterone on post-myocardial infarction remodelling in female rats". J Physiol Pharmacol, 58 (4), 2007 pp. $717-27$.

[41] Hsieh, S. R., W. C. Cheng, Y. M. Su, C. H. Chiu, and Y. M. Liou, "Molecular targets for anti-oxidative protection of green tea polyphenols against myocardial ischemic injury". Biomedicine (Taipei), 4, 2014, pp. 23.

[42] Annibalini, G., D. Agostini, C. Calcabrini, C. Martinelli, E. Colombo, M. Guescini, P. Tibollo, V. Stocchi, and P. Sestili, "Effects of sex hormones on inflammatory response in male and female vascular endothelial cells". J Endocrinol Invest, 37 (9), 2014, pp. 861-9. 
[43] Gupta, S., J. K. Gambhir, O. Kalra, A. Gautam, K. Shukla, M. Mehndiratta, S. Agarwal, and R. Shukla, "Association of biomarkers of inflammation and oxidative stress with the risk of chronic kidney disease in Type 2 diabetes mellitus in North Indian population". J Diabetes Complications, 27 (6), 2013, pp. 548-52.

[44] Glintborg, D., M. Andersen, B. Richelsen, and J. M. Bruun, "Plasma monocyte chemoattractant protein-1 (MCP-1) and macrophage inflammatory protein-1alpha are increased in patients with polycystic ovary syndrome (PCOS) and associated with adiposity, but unaffected by pioglitazone treatment". Clin Endocrinol (Oxf), 71 (5), 2009, pp. 652-8.

[45] Albuquerque, K. F., M. P. Marinovic, A. C. Morandi, A. P. Bolin, and R. Otton, "Green tea polyphenol extract in vivo attenuates inflammatory features of neutrophils from obese rats". Eur J Nutr, 55 (3), 2016, pp. 1261-74.

[46] Molina, N., A. P. Bolin, and R. Otton, "Green tea polyphenols change the profile of inflammatory cytokine release from lymphocytes of obese and lean rats and protect against oxidative damage". Int Immunopharmacol, 28 (2), 2015, pp. 985-96.
[47] Cai, J., Y. Hong, C. Weng, C. Tan, J. Imperato-McGinley, and Y.-S. Zhu, "Androgen stimulates endothelial cell proliferation via an androgen receptor/VEGF/cyclin A-mediated mechanism". American Journal of Physiology - Heart and Circulatory Physiology, 300 (4), 2011, pp. H1210-H1221.

[48] Chen, Y., L. Fu, Y. Han, Y. Teng, J. Sun, R. Xie, and J. Cao, "Testosterone replacement therapy promotes angiogenesis after acute myocardial infarction by enhancing expression of cytokines HIF-1a, SDF-1a and VEGF". Eur J Pharmacol, 684 (1-3), 2012, pp. 116-24.

[49] Hwang, E. C., K. J. Oh, S. I. Jung, N. N. Kim, K. Y. Ahn, and K. Park, "Effects of androgen on the expression of vascular endothelial growth factor in the penile corpus cavernosum". Urology, 77 (6), 2011, pp. 1381-6.

[50] Machova Urdzikova, L., J. Ruzicka, K. Karova, A. Kloudova, B. Svobodova, A. Amin, J. Dubisova, M. Schmidt, S. Kubinova, M. Jhanwar-Uniyal, and P. Jendelova, "A green tea polyphenol epigallocatechin-3-gallate enhances neuroregeneration after spinal cord injury by altering levels of inflammatory cytokines". Neuropharmacology, 126, 2017, pp. 213-223. 